\title{
A NOVEL FIVE-PHASE MATRIX-CONVERTER USING SPACE VECTOR MODULATION CONTROL ALGORITHM
}

\author{
Essam M. Rashad and Sheriff M. Dabour \\ Faculty of Engineering-Tanta University-Egypt
}

\begin{abstract}
In this paper the control algorithm for a novel five-phase matrix converter under balanced input voltage conditions is proposed. This algorithm is essentially based on the indirect space vector modulation. The complete algorithm, analysis and the model of the proposed matrix converter are introduced. The model has been applied for the case of inductive loads. The simulation results of input-output voltages and current waveforms are presented. Finally, the results show that fivephase matrix converter based on space vector modulation can be implemented.

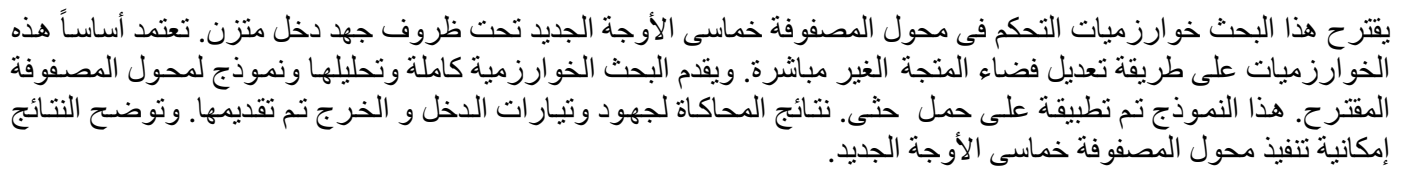

Keywords: AC-AC power conversion, five-phase matrix converter, Indirect Space Vector Modulation

\section{INTRODUCTION}

AC-AC power converters transform a constant voltage constant frequency supply into a variable voltage with variable frequency output required for many applications, as the adjustable speed drives. There are two kinds of AC-AC converter topologies, as shown in Fig.1:

- DC-Link converters (AC-DC-AC)

- Direct AC-AC converters

DC link converters have the disadvantage of large capacitor for the voltage source inverters or large inductor for the current source inverters. These disadvantages are overcome by direct AC-AC converters.

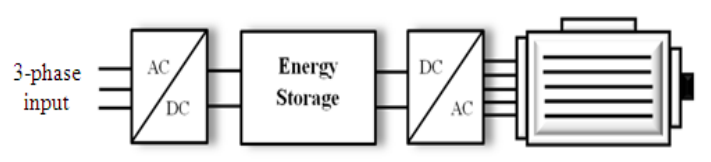

(a)

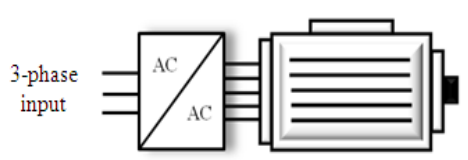

(b)

Fig.1 Ac/ac converter (a) indirect, (b) direct
Now the matrix converter is the superior of direct AC-AC converters. Was firstly introduced in 1976 and it steadily growth, pushed by the progress of the power electronics device technology. In recent years the matrix converter has received an increased amount of interest and has been studied intensely as an alternative to conventional AC-DC-AC power converter systems.

This paper proposes a new matrix converter which converts the ac power from three-phase to five-phase when supplying inductive loads.

\section{FIVE-PHASE MATRIX CONVERTER TOPOLOGY}

The analysis of the proposed system can be achieved using either of two strategies:
a) Direct Matrix Converter (DMC), and
b) Indirect Matrix Converter (IMC).

\section{Direct Five-Phase Matrix Converter}

The direct five-phase matrix converter is a direct three-phase to five-phase through one stage; it utilizes fifteen switches, as shown in Fig.2. Each of the fifteen switches depicted is a bidirectional switch, which are connected so that any of the input phases (A, B, and C) can be connected to any of the 
output phases; (a, b, c, d, and e) for a given switching.

With the fifteen bi-directional switches, the Matrix Converter has $2^{15}$ different switching states. Some of the basic rules or constrains must be regarded when applying different switching states to the Matrix Converter at any switching time. These rules are:

- The input phases must never be shorted, and

- The output phases must not be left open, due to the inductive nature of the load.

Due to the above constraints, the switching states reduce to $3^{5}$ different switching combinations for connecting output phases to input phases.

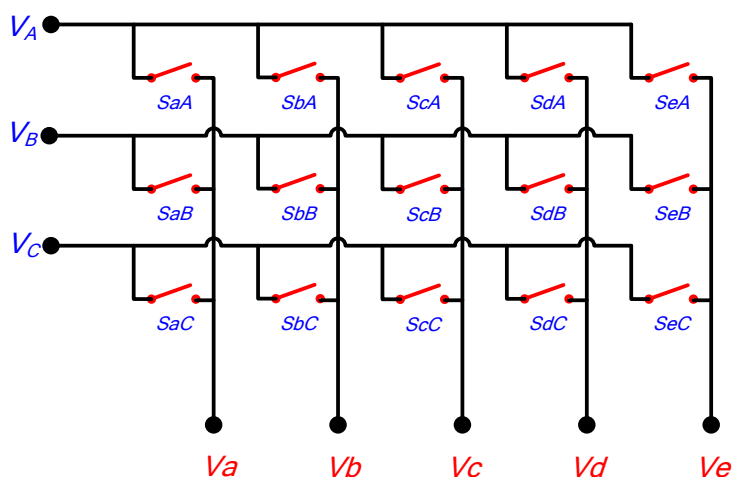

Fig.2 Direct Five-phase Matrix converter topology.

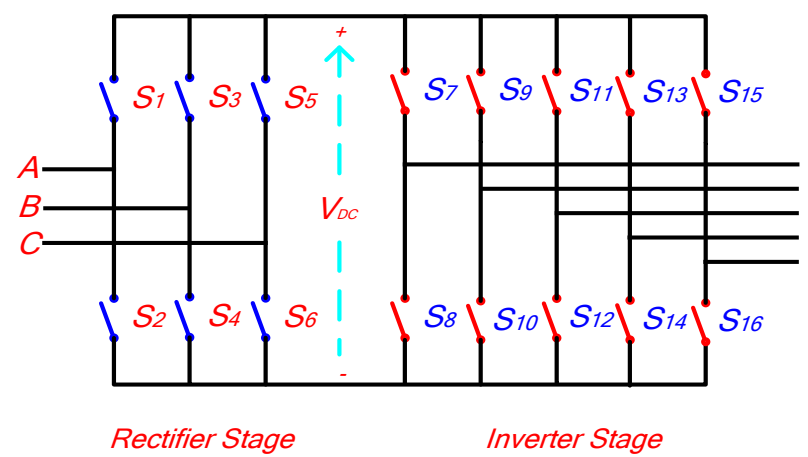

Fig.3 Indirect Five-phase Matrix converter topology

The output voltages $v_{0}\left(v_{a} v_{b} v_{c} v_{d} v_{e}\right)$ and the input currents $i_{i}\left(\begin{array}{llll}i_{A} & i_{B} & i_{C}\end{array}\right)$ are therefore derived directly from the input voltages $v_{i}\left(v_{A} v_{B} v_{C}\right)$, and the output currents $i_{o}\left(i_{a} i_{b} i_{c} i_{d} i_{e}\right)$ as following.

$$
\begin{aligned}
& {\left[v_{0}\right]=[S]_{0}\left[v_{i}\right]} \\
& {\left[i_{i}\right]=[S]^{T} \cdot\left[i_{0}\right]}
\end{aligned}
$$

where, $S$ is the modulation matrix or the duty cycles of the switches.

$$
S=\left[\begin{array}{lll}
S_{a A} & S_{a B} & S_{a C} \\
S_{b A} & S_{b B} & S_{b C} \\
S_{C A} & S_{a B} & S_{a C} \\
S_{d A} & S_{d B} & S_{d C} \\
S_{a A} & S_{a B} & S_{a C}
\end{array}\right]
$$

\section{Indirect Five-Phase Matrix Converter}

This topology to model the matrix converter actually corresponds to regard the matrix converter as a double-PWM converter without any DC-Link energy storage, where matrix converter was described to an equivalent model combining current source rectifier and voltage source inverter connected through virtual dc link and it was first proposed by [6] for three phase to three-phase matrix converter, and by applying this algorithm on the direct five-phase matrix converter, the resulting indirect five-phase matrix converter is shown in Fig. 3.

The rectifier stage has the same topology of the three-phase rectifier with six switches, $S_{1} \sim S_{6}$, and the Inverter stage has a standard five-phase voltage source inverter topology consisting of ten switches, $S_{7} \sim S_{16}$. Both power stages are directly connected through virtual dc-link and inherently provide bidirectional power flow capability because of its symmetrical topology.

\section{SPACE VECTOR MODULATION OF THE PROPOSED CONVERTER}

The space vector modulation (SVM) technique constructs the desired sinusoidal output five-phase voltage by selecting the valid switching states of a matrix converter and calculating their corresponding on-time durations.

${ }_{a}$ Basic idea of the indirect modulation is to decouple $b$ the control of the input current and the control of $c_{d}$ output voltage. This is done by splitting the emodulation matrix $\mathrm{S}$ for the converter into the product of a rectifier transfer function $\mathrm{R}$ and an inverter transfer function I. The modulation matrix for the Matrix Converter is thus defined as following [3], [4]:

$S=I . R$

Where $I=\left[\begin{array}{cc}s_{7} & s_{8} \\ s_{9} & s_{10} \\ s_{11} & s_{12} \\ s_{13} & s_{14} \\ s_{15} & s_{16}\end{array}\right]$

And $R=\left[\begin{array}{lll}s_{1} & s_{3} & s_{5} \\ s_{2} & s_{4} & s_{6}\end{array}\right]$

Therefore 
$S=$

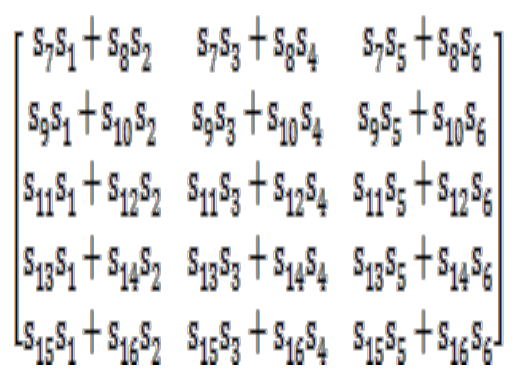

The above transfer matrix exhibits that the output phases are compounded by the product and sum of the input phases through rectifier switches S1 S6 and inverter switches S7 S16.

$$
\left[\begin{array}{l}
v_{a} \\
v_{b} \\
v_{c} \\
v_{d} \\
v_{a}
\end{array}\right]=\left[\begin{array}{lll}
S_{a A} & S_{a B} & S_{a C} \\
S_{b A} & S_{b B} & S_{b C} \\
S_{c A} & S_{c B} & S_{c C} \\
S_{d A} & S_{d B} & S_{d C} \\
S_{\theta A} & S_{a B} & S_{\theta C}
\end{array}\right]\left[\begin{array}{c}
v_{A} \\
v_{B} \\
v_{C}
\end{array}\right]
$$

The first row of the above matrix represents how output phase a is built from the input phase A, B and $\mathrm{C}$ for the direct $\mathrm{MC}$ using indirect topology and this mathematical expression can be interpreted again in the graphical viewpoint as shown in Fig. 4.

Based on the indirect modulation technique the following sections describe two independent space vector modulations for three-phase current source rectifier, and five-phase voltage source inverter stages and then the two modulation results are combined to modulate the five-phase matrix converter.

\section{Space Vector Rectifier (SVR)}

The rectifier converts the input three-phase voltage to DC-voltage. At the same time the rectifier algorithm assures the input currents to be sinusoidal. This section introduces a space vector PWM in the rectifier stage. The rectifier part of the equivalent model shown in Fig. 3 can be assumed to be a standalone current source rectifier (CSR) as shown in Fig. 5.

In the indirect space vector modulation, all quantities are referred to a virtual dc link which is obtained by chop of the input voltages.

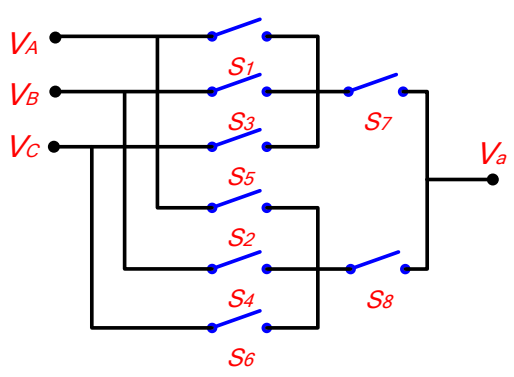

(a)

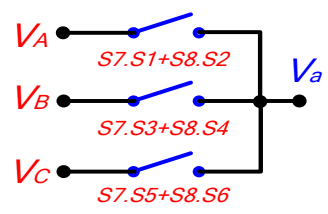

(b)

Fig. 4 Transformation from indirect model to direct matrix converter in phase a (a) Phase A of indirect model, and (b) Phase a of direct model

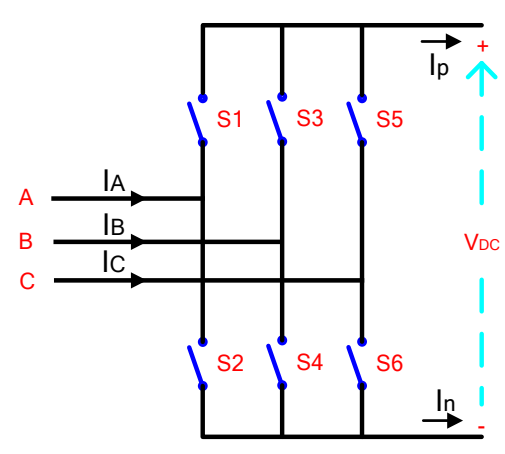

Fig.5 Rectifier stage topology

The input currents can be represented as the virtual dc-link current IDC multiplied by the switching states of rectifier transfer function R given by eq. (6) as following;

$$
\left[\begin{array}{l}
I_{A} \\
I_{B} \\
I_{C}
\end{array}\right]=\left[\begin{array}{ll}
S_{1} & S_{2} \\
S_{3} & S_{4} \\
S_{5} & S_{6}
\end{array}\right] \cdot\left[\begin{array}{l}
I_{p} \\
I_{n}
\end{array}\right]
$$

Then the input current IIN is expressed as space vectors as following;

$I_{I N}=\frac{2}{3}\left(I_{A}+a \cdot I_{B}+a^{2} \cdot I_{C}\right)=\left|I_{I N}\right| e^{j \alpha_{i}}$

The rectifier switches, S1 S6 can have only possible nine allowed combinations to avoid an open circuit at the dc link rails. The nine combinations can be divided into six nonzero input currents which are active vector $\mathrm{I} 1 \sim \mathrm{I} 6$ and three zero input currents which are zero vector I7 I9, as in Table 1, and Fig. 6 shows current space vector hexagon. 
Table 1, Switching states and switching vectors for the Rectifier side

\begin{tabular}{|c|c|c|c|c|c|c|}
\hline Vectors & $\begin{array}{c}\text { On } \\
\text { switch }\end{array}$ & $I_{A}$ & $I_{x}$ & $I_{\varepsilon}$ & $I_{I N}$ & $\alpha_{i}$ \\
\hline $\mathrm{I}_{1}$ & S1S4 & $L_{D}$ & $-I_{0}$ & 0 & $\frac{2}{\sqrt{3}} F_{b}$ & $-\pi / 6$ \\
\hline $\mathrm{I}_{2}$ & S1S6 & $L_{b}$ & 0 & $-I_{D}$ & $\frac{2}{\sqrt{2}} I_{D}$ & $\pi / 6$ \\
\hline $\mathrm{I}_{3}$ & S3S6 & 0 & $L_{b}$ & $I_{b}$ & $\frac{2}{\sqrt{3}} I_{0}$ & $\pi / 2$ \\
\hline $\mathrm{I}_{4}$ & S2S3 & $-I_{b}$ & $L_{b}$ & 0 & $\frac{2}{\sqrt{2}} I_{b}$ & $5 \pi / 6$ \\
\hline $\mathrm{I}_{5}$ & S2S5 & $-I_{v}$ & 0 & $L_{b}$ & $\frac{2}{\sqrt{3}} I_{D}$ & $\begin{array}{l}- \\
5 \pi / 6\end{array}$ \\
\hline $\mathrm{I}_{6}$ & S4S5 & 0 & $-I_{p}$ & b & $\frac{x}{\sqrt{2}} I_{p}$ & $-\pi / 2$ \\
\hline $\mathrm{I}_{7}$ & S1S2 & 0 & 0 & 0 & 0 & 0 \\
\hline $\mathrm{I}_{8}$ & S3S4 & 0 & 0 & 0 & 0 & 0 \\
\hline $\mathrm{I}_{9}$ & S5S6 & 0 & 0 & 0 & 0 & 0 \\
\hline
\end{tabular}

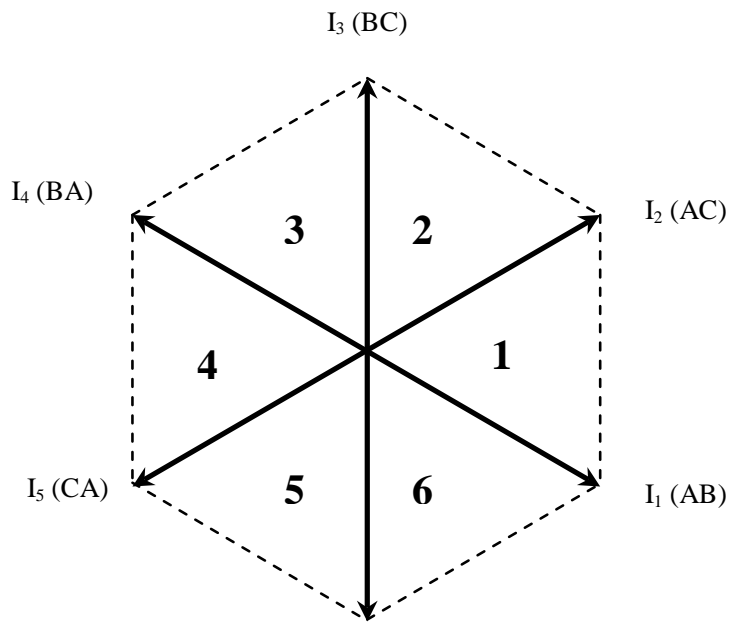

$\mathrm{I}_{6}(\mathrm{CB})$

Fig. 6 Rectifier current hexagon

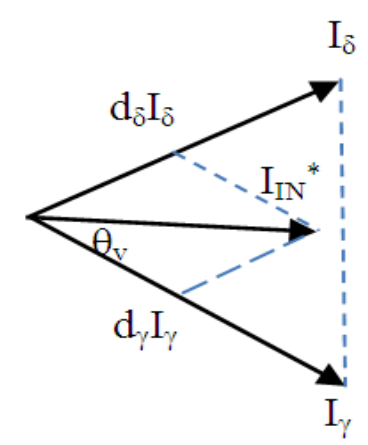

If the input currents are considered constant during a short switching interval TS, the reference vector can be expressed by the current-time product sum of the adjacent active vectors as;

$I_{I N}^{*}=d_{y} \cdot I_{y}+d_{\delta} \cdot I_{\delta}+d_{o} \cdot I_{o}$

Thus, the duty cycle of the active vectors are written as;

$$
\begin{aligned}
& d_{y}=m_{c} \cdot \sin \left(\frac{\pi}{3}-\theta_{c}\right) \\
& d_{\delta}=m_{c} \cdot \sin \left(\theta_{c}\right) \\
& d_{o}=1-\left(d_{y}-d_{\delta}\right)
\end{aligned}
$$

where, $\theta_{\mathrm{C}}$ indicates the angle of the reference current vector within the actual hexagon sector. The $m_{C}$ is the current modulation index and defines the desired current transfer ratio such as

$$
\begin{gathered}
0 \leq m_{C} \leq 1 \\
m_{C}=\frac{I_{I N}^{*}}{I_{D C}}
\end{gathered}
$$

The current modulation index $\mathrm{mC}$ is often fixed to unity and the voltage modulation index $\mathrm{mV}$ is variable according to a required overall voltage transfer gain.

\section{Space Vector Inverter (SVI)}

This section introduces a space vector PWM in the inverter stage. Consider the inverter part of the equivalent model in Fig. 3 as a standalone VSI supplied by a dc voltage source, as shown in Fig.8. The power conversion is performed via the virtual dc-link of VDC.

where, $\mathrm{VDC}=\mathrm{Vp}-\mathrm{Vn}$

The output voltages can be obtained by multiplying the virtual dc-link voltage VDC by inverter transfer function I so that:

$\left[\begin{array}{l}V_{a} \\ V_{b} \\ V_{c} \\ V_{d} \\ V_{e}\end{array}\right]=\left[\begin{array}{ll}s_{7} & s_{8} \\ s_{9} & s_{10} \\ s_{11} & s_{12} \\ s_{13} & s_{14} \\ s_{15} & s_{16}\end{array}\right] \cdot\left[\begin{array}{c}\frac{V_{D C}}{2} \\ \frac{-V_{D C}}{2}\end{array}\right]$

Fig.7 Synthesis of reference current vector $\left(\mathrm{m}_{\mathrm{c}}=1\right)$

Figure 7 shows the reference input current vector $\mathrm{I}_{\mathrm{IN}} *$ within a sector of the current hexagon. The $\mathrm{I}_{\mathrm{IN}}$ * is synthesized by impressing the adjacent switching vectors $I \gamma$ and $I \delta$ with the duty cycles $\mathrm{d} \gamma$ and $\mathrm{d} \delta$, respectively. 


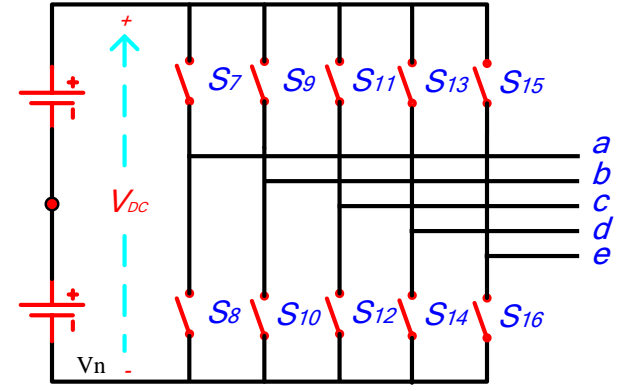

Fig. 8 Inverter stage from of indirect five-phase matrix converter

Then the output voltage space vector is expressed as a function of phase voltages as follows:

$$
\begin{aligned}
V_{\text {out }} & =\frac{2}{5}\left(V_{a}+b \cdot V_{b}+b^{2} \cdot V_{c}+b^{3} \cdot V_{d}+b^{4} \cdot V_{a}\right) \\
& =\left|V_{\text {out }}\right| e^{j \alpha_{o}}
\end{aligned}
$$

where, $b=e^{j 2 \pi / 5}$, V OUT is the output voltage, and $\alpha_{o}$ is the space vector angle. The inverter switches, S7 - S16 have only thirty two allowed combinations to avoid a short circuit through five half bridges. The thirty two combinations have thirty nonzero output voltages or active vectors $\left(\mathrm{V}_{1}\right.$ to $\left.\mathrm{V}_{30}\right)$ and two zero output voltages or zero vector $\mathrm{V}_{0}$ as shown in Table 2. The discrete thirty two space vectors can be represented as a decagon in a complex plane shown in Fig. 9.

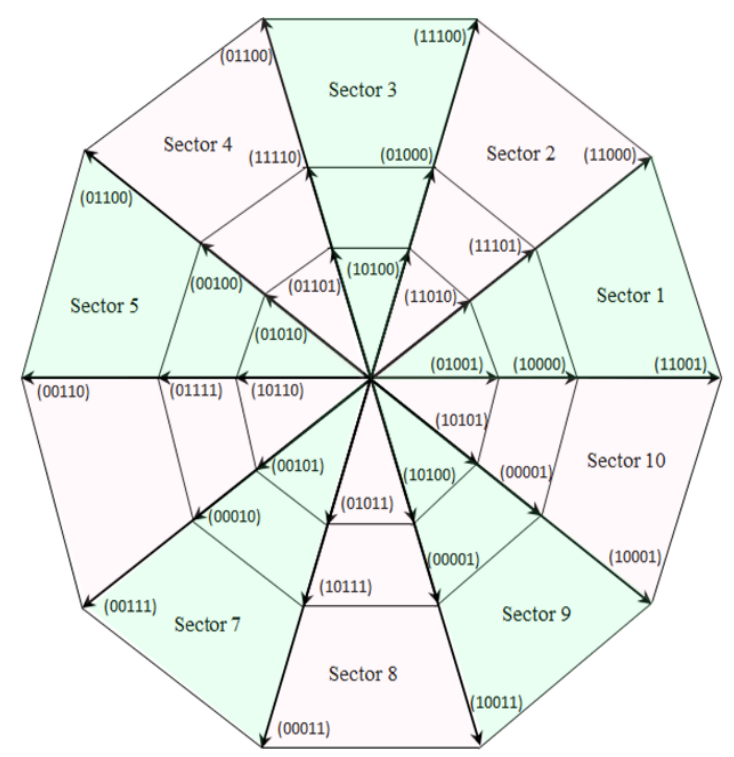

Fig.9 The inverter stage decagon
Table 2, switching states and switching vectors for

\begin{tabular}{|c|c|c|c|c|c|c|c|}
\hline Vectors & $V_{a}$ & $V_{b}$ & $V_{\varepsilon}$ & $V_{d}$ & $V_{\mathrm{e}}$ & $V_{\text {eut }}$ & $\alpha_{\infty}$ \\
\hline $\mathrm{V}_{1}(11001)$ & $\frac{V_{p c}}{z}$ & $\frac{V_{n c}}{x}$ & $\frac{-w_{s c}}{z}$ & $\frac{-w_{s c}}{z}$ & $\frac{V_{v e}}{z}$ & $0.6472 V_{D E}$ & 0 \\
\hline $\mathrm{V}_{2}(11000)$ & $\frac{V_{n s}}{x}$ & $\frac{V_{n c}}{z}$ & $\frac{-V_{v e}}{z}$ & $\frac{-V_{v c}}{z}$ & $\frac{-V_{v c}}{z}$ & $0.6472 V_{D e}$ & $\pi / 5$ \\
\hline $\mathrm{V}_{3}(11100)$ & $\frac{v_{n c}}{z}$ & $\frac{y_{D E}}{x}$ & $\frac{V_{D E}}{x}$ & $\frac{-w_{D E}}{z}$ & $\frac{-v_{x c}}{z}$ & $0.6472 V_{D e}$ & $2 \pi / 5$ \\
\hline $\mathrm{V}_{4}(01100)$ & $\frac{-w_{D E}}{z}$ & $\frac{V_{D C}}{x}$ & $\frac{V_{s c}}{z}$ & $\frac{-w_{D E}}{z}$ & $\frac{-v_{D E}}{z}$ & $0.6472 V_{D e}$ & $3 \pi / 5$ \\
\hline $\mathrm{V}_{5}(01110)$ & $\frac{-v_{s c}}{x}$ & $\frac{V_{D C}}{z}$ & $\frac{V_{s c}}{z}$ & $\frac{V_{D c}}{z}$ & $\frac{-v_{D S}}{z}$ & $0.6472 V_{o c}$ & $4 \pi / 5$ \\
\hline $\mathrm{V}_{6}(00110)$ & $\frac{-w_{D S}}{z}$ & $\frac{-w_{L S}}{x}$ & $\frac{V_{D x}}{z}$ & $\frac{V_{v e}}{z}$ & $\frac{-v_{s c}}{z}$ & $0.6472 V_{D e}$ & $\pi$ \\
\hline $\mathrm{V}_{7}(00111)$ & $\frac{-v_{s c}}{z}$ & $\frac{-w_{S C}}{z}$ & $\frac{V_{D S}}{z}$ & $\frac{V_{x c}}{z}$ & $\frac{V_{s c}}{z}$ & $0.6472 V_{D e}$ & $-4 \pi / 5$ \\
\hline $\mathrm{V}_{8}(00011)$ & $\frac{-w_{s c}}{z}$ & $\frac{-w_{s c}}{z}$ & $\frac{-v_{\text {se }}}{x}$ & $\frac{F_{D E}}{x}$ & $\frac{F_{D E}}{z}$ & $0.6472 V_{D c}$ & $-3 \pi / 5$ \\
\hline $\mathrm{V}_{9}(10011)$ & $\frac{V_{v e}}{x}$ & $\frac{-w_{s c}}{z}$ & $\frac{-w_{s c}}{z}$ & $\frac{F_{n c}}{z}$ & $\frac{F_{v e}}{x}$ & $0.6472 V_{D E}$ & $-2 \pi / 5$ \\
\hline$V_{10}(10001)$ & $\frac{v_{D S}}{z}$ & $\frac{-v_{L S}}{2}$ & $\frac{-v_{D S}}{x}$ & $\frac{-v_{D S}}{z}$ & $\frac{V_{D S}}{z}$ & $0.6472 V_{D e}$ & $-\pi / 5$ \\
\hline$V_{11}(10000)$ & $\frac{V_{s c}}{z}$ & $\frac{-v_{L S}}{2}$ & $\frac{-v_{D S}}{x}$ & $\frac{-V_{D S}}{z}$ & $\frac{-w_{D E}}{z}$ & $0.4 V_{b e}$ & 0 \\
\hline$V_{12}(11101)$ & $\frac{V_{v e}}{z}$ & $\frac{V_{D c}}{z}$ & $\frac{V_{D E}}{z}$ & $\frac{-w_{D E}}{z}$ & $\frac{V_{\text {se }}}{z}$ & $0.4 V_{D e}$ & $\pi / 5$ \\
\hline $\mathrm{V}_{13}(01000)$ & $\frac{-v_{s c}}{x}$ & $\frac{V_{D E}}{x}$ & $\frac{-w_{s c}}{x}$ & $\frac{-V_{D S}}{z}$ & $\frac{-v_{D c}}{z}$ & $0.4 V_{D e}$ & $2 \pi / 5$ \\
\hline$V_{14}(11110)$ & $\frac{V_{s c}}{z}$ & $\frac{V_{D C}}{z}$ & $\frac{V_{D E}}{z}$ & $\frac{V_{\text {se }}}{z}$ & $\frac{-v_{S E}}{z}$ & $0.4 V_{D E}$ & $3 \pi / 5$ \\
\hline$V_{15}(10100)$ & $\frac{-v_{D s}}{z}$ & $\frac{-w_{D S}}{z}$ & $\frac{v_{D E}}{x}$ & $\frac{-W_{D S}}{z}$ & $\frac{-w_{s c}}{x}$ & $0.4 V_{D E}$ & $4 \pi / 5$ \\
\hline $\mathrm{V}_{16}(01111)$ & $\frac{-v_{v g}}{x}$ & $\frac{V_{n E}}{z}$ & $\frac{V_{D E}}{z}$ & $\frac{V_{p E}}{z}$ & $\frac{v_{D s}}{z}$ & $0.4 V_{b e}$ & $\pi$ \\
\hline$V_{17}(00010)$ & $\frac{-v_{s c}}{z}$ & $\frac{-y_{s c}}{z}$ & $\frac{-w_{s c}}{z}$ & $\frac{V_{x c}}{x}$ & $\frac{-v_{D S}}{z}$ & $0.4 V_{D E}$ & $-4 \pi / 5$ \\
\hline $\mathrm{V}_{18}(10111)$ & $\frac{V_{L S}}{z}$ & $\frac{-w_{D S}}{2}$ & $\frac{V_{D S}}{z}$ & $\frac{V_{D S}}{z}$ & $\frac{V_{D S}}{z}$ & $0.4 V_{\mathrm{be}}$ & $-3 \pi / 5$ \\
\hline $\mathrm{V}_{19}(10111)$ & $\frac{-V_{D S}}{z}$ & $\frac{-w_{D s}}{x}$ & $\frac{-v_{s c}}{2}$ & $\frac{-V_{D S}}{x}$ & $\frac{v_{D E}}{z}$ & $0.4 V_{b e}$ & $-2 \pi / 5$ \\
\hline $\mathrm{V}_{20}(11011)$ & $\frac{V_{s c}}{x}$ & $\frac{V_{n c}}{z}$ & $\frac{-v_{s c}}{x}$ & $\frac{V_{n c}}{z}$ & $\frac{y_{v e}}{z}$ & $0.4 V_{D E}$ & $-\pi / 5$ \\
\hline $\mathrm{V}_{21}(01001)$ & $\frac{-V_{s e}}{z}$ & $\frac{V_{n c}}{z}$ & $\frac{-w_{s c}}{z}$ & $\frac{-w_{D s}}{z}$ & $\frac{V_{n s}}{z}$ & $0.2472 V_{\text {of }}$ & 0 \\
\hline $\mathrm{V}_{22}(11010)$ & $\frac{V_{x c}}{z}$ & $\frac{V_{D E}}{z}$ & $\frac{-w_{D x}}{x}$ & $\frac{V_{x c}}{z}$ & $\frac{-v_{D S}}{z}$ & $0.2472 V_{D e}$ & $\pi / 5$ \\
\hline $\mathrm{V}_{23}(11010)$ & $\frac{v_{t s c}}{z}$ & $\frac{-w_{D s}}{x}$ & $\frac{V_{x c}}{z}$ & $\frac{-w_{D E}}{z}$ & $\frac{-v_{s c}}{z}$ & $0.2472 V_{D E}$ & $2 \pi / 5$ \\
\hline $\mathrm{V}_{24}(11010)$ & $\frac{-v_{s c}}{z}$ & $\frac{V_{s c}}{x}$ & $\frac{V_{s c}}{z}$ & $\frac{-y_{D E}}{z}$ & $\frac{V_{n c}}{z}$ & $0.2472 V_{D E}$ & $3 \pi / 5$ \\
\hline $\mathrm{V}_{25}(11010)$ & $\frac{-w_{n c}}{z}$ & $\frac{V_{D C}}{x}$ & $\frac{-v_{s c}}{z}$ & $\frac{V_{v e}}{z}$ & $\frac{-w_{p c}}{z}$ & $0.2472 V_{D E}$ & $4 \pi / 5$ \\
\hline $\mathrm{V}_{26}(10110)$ & $\frac{V_{L C E}}{z}$ & $\frac{-w_{L S}}{x}$ & $\frac{V_{D E}}{z}$ & $\frac{v_{\text {se }}}{z}$ & $\frac{-v_{s c}}{z}$ & $0.2472 V_{D E}$ & $\pi$ \\
\hline $\mathrm{V}_{27}(00101)$ & $\frac{-v_{s c}}{x}$ & $\frac{-W_{D S}}{2}$ & $\frac{V_{L E}}{2}$ & $\frac{-v_{s c}}{z}$ & $\frac{v_{s c}}{z}$ & $0.2472 V_{D E}$ & $-4 \pi / 5$ \\
\hline $\mathrm{V}_{28}(01011)$ & $\frac{-w_{s c}}{x}$ & $\frac{V_{D E}}{x}$ & $\frac{-v_{s c}}{x}$ & $\frac{V_{D E}}{x}$ & $\frac{V_{D S}}{z}$ & $0.2472 V_{D E}$ & $-3 \pi / 5$ \\
\hline $\mathrm{V}_{29}(10010)$ & $\frac{V_{D S}}{z}$ & $\frac{-w_{D s}}{2}$ & $\frac{-v_{D E}}{z}$ & $\frac{V_{n c}}{x}$ & $\frac{-v_{s c}}{z}$ & $0.2472 V_{c e}$ & $-2 \pi / 5$ \\
\hline $\mathrm{V}_{30}(10101)$ & $\frac{V_{s c}}{z}$ & $\frac{-w_{D S}}{z}$ & $\frac{V_{D E}}{z}$ & $\frac{-v_{v e}}{z}$ & $\frac{V_{D S}}{z}$ & $0.2472 V_{b e}$ & $-\pi / 5$ \\
\hline $\mathrm{V}_{31}(00000)$ & $\frac{-v_{s c}}{x}$ & $\frac{-W_{D S}}{x}$ & $\frac{-w_{D s}}{z}$ & $\frac{-w_{D S}}{z}$ & $\frac{-w_{s c}}{x}$ & 0 & 0 \\
\hline $\mathrm{V}_{32}(11111)$ & $\frac{V_{n s}}{x}$ & $\frac{F_{D c}}{x}$ & $\frac{V_{t s c}}{z}$ & $\frac{V_{n c}}{z}$ & $\frac{V_{n c}}{z}$ & 0 & 0 \\
\hline
\end{tabular}
the inverter side 
The space vector scheme reviewed here considers the outer most and the intermediate decagons of space vectors in d-q plane as shown in Fig.10.

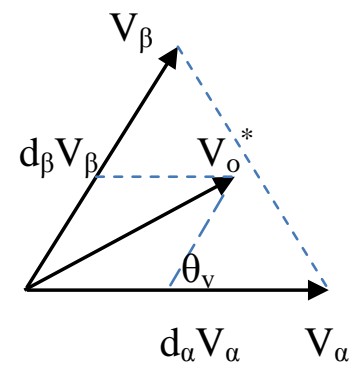

Fig.10 Synthesis of reference voltage vector

Figure 10 shows the outermost decagon of the input reference voltage vector $\mathrm{Vo}^{*}$ within a sector of the voltage decagon. The $\mathrm{Vo}^{*}$ is synthesized by impressing the adjacent voltage vectors $V_{\alpha}$ and $V_{\beta}$ with the duty cycles $d_{\alpha}$ and $d_{\beta}$, respectively.

$d_{\alpha}=m_{v^{*}} \sin \left(\pi / 5-\theta_{v}\right)$

$d_{\beta}=m_{v} \sin \left(\theta_{v}\right)$

where

$m_{v}=\frac{V_{o}^{8}}{V_{l} \sin (4 \pi / 5)}$

$V_{l}=0.6472 V_{D C}$

Therefore maximum fundamental peak output voltage $\mathrm{V}_{\max }$ is given by:

$$
\begin{aligned}
V_{\max } & =0.6472 V_{D C} \cos \left(\frac{\pi}{10}\right) \\
& =0.6155 V_{D C}
\end{aligned}
$$

Space vector modulation with large and medium vectors is based on the proportional sub-division of the time of application of each vector from outer and intermediate sectors. The times obtained are subdivided according to the ratio of medium and large vector lengths, so that the duty ratios are given by:

$$
\begin{aligned}
& d_{\alpha l}=d_{\alpha} \frac{V_{I}}{V_{l}+V_{m}} \\
& d_{\alpha m}=d_{\alpha} \frac{V_{m}}{V_{l}+V_{m}} \\
& d_{\beta l}=d_{\beta} \frac{V_{I}}{V_{l}+V_{m}}
\end{aligned}
$$

$$
d_{\beta m}=d_{\beta} \frac{V_{m}}{V_{l}+V_{m}}
$$

where, $V_{m}=0.4 V_{D C}$

The time of zero space vectors application can be obtained so that its duty ratio $d_{o}$ is given by:

$d_{o}=1-\left(d_{\alpha l}+d_{\alpha m}+d_{\beta l}+d_{\beta m}\right)$

To minimize the number of the inverter-switching, the sequence of the impressed voltage vectors is given by:

$$
V_{\alpha m} \rightarrow V_{\beta l} \rightarrow V_{\alpha l} \rightarrow V_{\beta m} \rightarrow V_{o}
$$

\section{SIMULATION RESULT}

Simulation of the five-phase matrix converter has been performed with a passive RL load. The load parameters are $10 \Omega$ and $0.12 \mathrm{H}$. The converter is fed by a three-phase sinusoidal supply which has line voltage and frequency of $380 \mathrm{~V}$ and $50 \mathrm{~Hz}$, respectively. The switches are controlled using the indirect space vector modulation method described above at switching frequency of $6-\mathrm{kHz}$. Three values of output frequencies have been considered, namely 30, 50, and 70-Hz.

Figures 11, 12, and 13 describe the output line voltage and load currents of the MC for the above mentioned conditions. This figure shows very clearly the validity of the proposed model of the MC.

The RL load currents are near sinusoidal currents. In addition, it can be observed that the matrix converter can generate output frequencies that are not restricted by the source frequency.

Figure 14 shows that the input current generated by the MC has the form of several pulses with a high $\mathrm{di} / \mathrm{dt}$, making it necessary to introduce an input filter to avoid the generation of over-voltages. This figure shows very clearly zero input current displacement angle i.e. unity input power factor of the MC. While Fig. 15 shows the virtual dc-link voltage.

Table 3 list the change in THD of the output current with the change of the output frequency.

Table 3, Total harmonic distortion for different output frequencies

\begin{tabular}{cc}
\hline Output frequency $(\mathrm{Hz})$ & $\%$ THD \\
20 & 4.84 \\
30 & 4.42 \\
50 & 4.13 \\
70 & 4.62 \\
100 & 5.21 \\
\hline
\end{tabular}




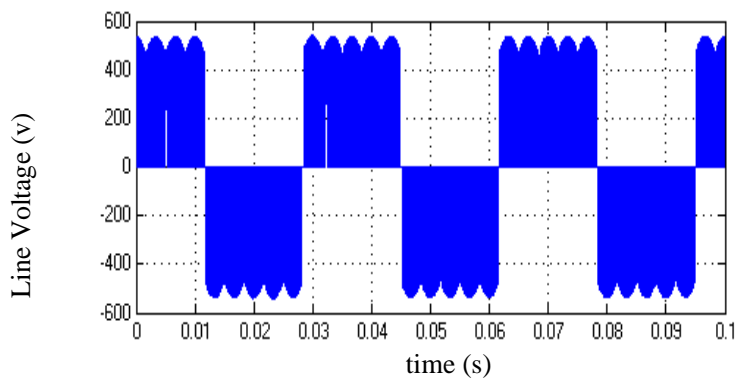

(a)

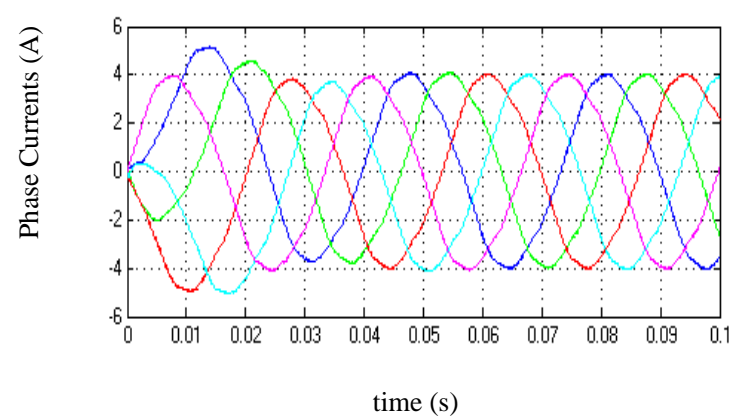

(b)

Fig. 11 For output frequency $30 \mathrm{~Hz}$ (a) output line voltage, (b) output five phase currents.

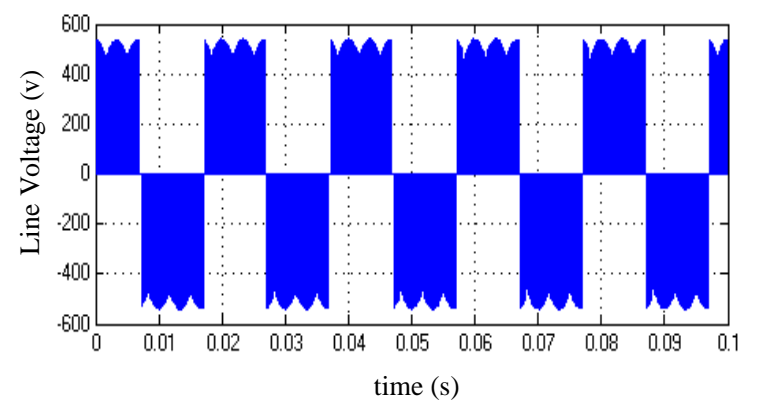

(a)

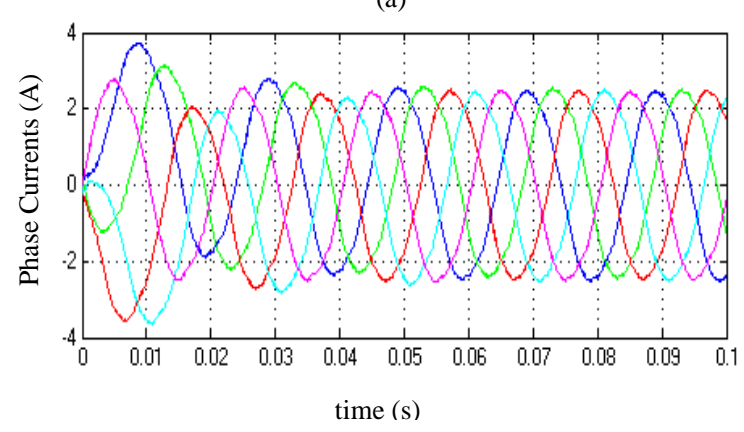

(b)

Fig.12 For output frequency $50 \mathrm{~Hz}$ (a) output line voltage, (b) output five phase currents.

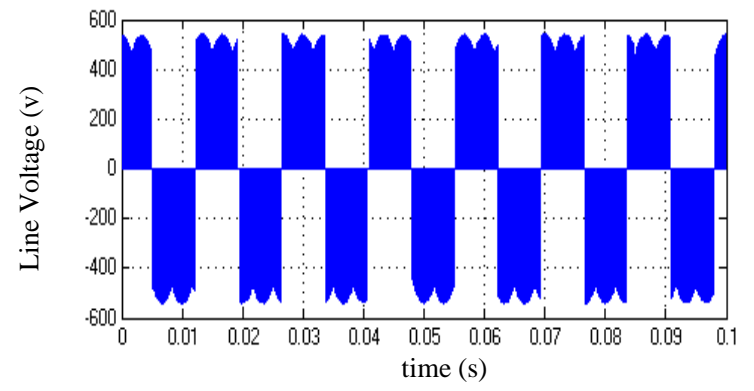

(a)

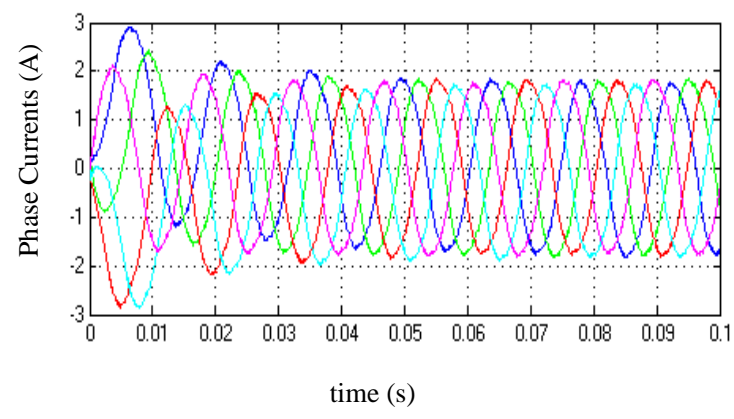

(b)

Fig. 13 For output frequency $70 \mathrm{~Hz}$ (a) output line voltage, (b) output five phase currents.

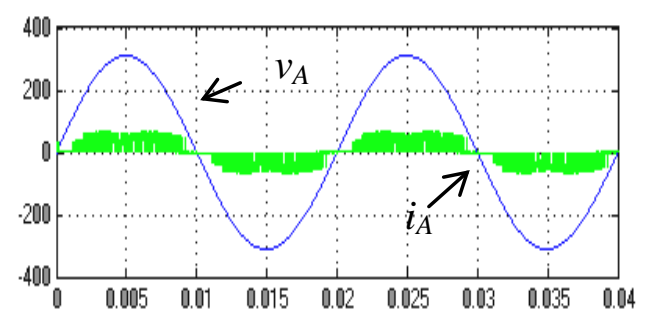

Fig.14 The input voltage $v_{A}$ and current $i_{A}$

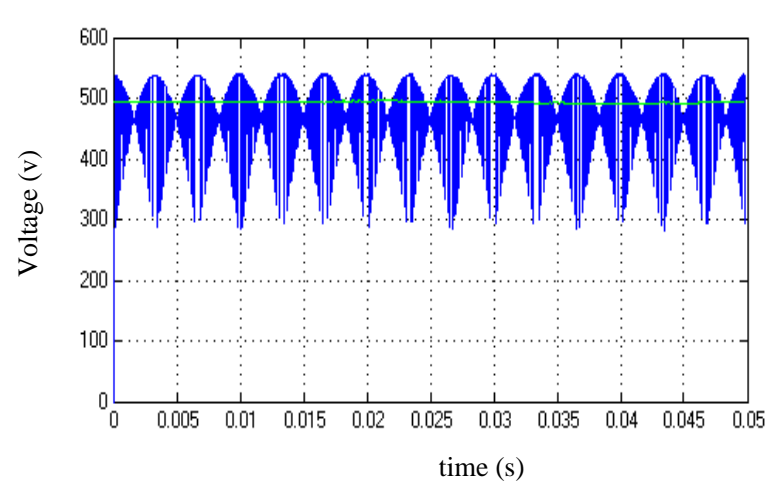

Fig.15 Virtual DC voltage at $m_{c}=1$, zero input current displacement angle, $220 \mathrm{v}$ input voltage, and input frequency $50 \mathrm{~Hz}$. 


\section{CONCLUSION}

This paper presents a novel three-phase to five-phase matrix converter based on the indirect space vector modulation algorithm. The converter has been considered as a combination of three-phase rectifier and five-phase inverter. Both rectifier and inverter are space vector modulated. Simulation results are presented for five phase passive load. According to the results obtained, the control algorithm presented is advisable for the establishing in the industry. An experimental implementation of the proposed system will be considered in future work.

\section{REFERENCES}

[1] M. Venturini, A New Sine Wave in Sine Wave out, Conversion Technique Which Eliminates Reactive Elements, Proceedings of Powercon 7, pp. E3/1-E3/15, 1980.

[2] A. Alesina, M. Venturini, “Analysis and Design of Optimum-Amplitude Nine Switch Direct AC-AC Converters", IEEE Trans. Power Electron., vol. 4, no.1, pp. 101-112, Jan. 1989.
[3] P. Nielsen, F. Blaabjerg, J.K.Pedersen: "Space Vector Modulated Matrix Converter with Minimized Number of Switchings and a Feedforward Compensation of Input Voltage Unbalance” Proceedings of PEDES’96 Vol II p. 833-839

[4] H. J. CHA, P. N. Enjeti: “Analysis and design of matrix converters for adjustable Speed drives and distributed power sources.” PhD, Texas A\&M University, August 2004

[5] A Iqbal and E Levi.: "Space Vector PWM Techniques for Sinusoidal Output Voltage Generation with a Five-phase Voltage Source Inverter." Electric Power Components and System, vol 34, no 2, February 2006

[6] $\mathrm{H} \mathrm{Xu}, \mathrm{H} \mathrm{A}$ Toliyat and L J Petersen. 'Fivephase Induction Motor Drives with DSP-based Control System.' IEEE Transactions on Power Electronics, vol 17, no 4, 2002, p 524.

[7] H.M.Ryu, J.H.Kim, and S.K.Sul: "Analysis of Multi-Phase Space Vector Pulse Width Modulation Based on Multiple d-q Spaces Concept.

[8] Bimal K.Bose, Modern Power Electronics and AC Drives, (C) 2002 Prentice Hall PTR. 